\title{
Construction Safety Problem Analysis in Building Structure Design
}

\author{
Zhu Jinhai \\ Guangxi Polytechnic of Modern Hechi Guangxi China 547000
}

Keywords: Building construction; Structure design; Security problems

\begin{abstract}
With the rapid development of construction industry, construction quality and safety problems are becoming more and more serious. Building structure design is related with the quality and security of the building. How to improve building structure design safety has become the focus of people. This paper points out that there are some security problems widespread in the design of building structures, expounds the characteristics and principles of building structure design, and puts forward some effective strategies for increasing the buildings safety in building design to ensure the safety of building design in our country and serve as a reference for further development of construction industry.

The scale of construction industry in our country is increasingly big and the design of building structure has become more and more complicated. There are still some problems in building design in China at present that cannot be ignored. Some construction enterprises pay too much attention to construction function and appearance and ignore the security. This results in frequent safety accidents. Structure designers, therefore, should strengthen the attention to construction quality and design reasonable and scientific plans to improve the security of building structure design.
\end{abstract}

\section{SECURITY PROBLEMS IN STRUCTURE DESIGN}

A. Building structure lacks earthquake resistance

In recent years, there are frequent earthquake disasters in multiple regions which are responsible for a large number of casualties. This affects people's life safety and property safety. People died in the earthquakes are mostly due to building collapse, and therefore, when the earthquake happens, people's life depends largely on the quality of the houses. Make sure that when earthquake disaster comes, people casualties can be reduced as far as possible. It is necessary to strengthen the structure of earthquake resistance and design strictly in accordance with the standards formulated by the state. Now many enterprises reduce the use amount of steel and concrete in the design of building structure in order to save costs, which leads to the weakening of building structure main body function. When there is an earthquake disaster, this will lead to structural instability and increase the possibility of collapse. On the other hand, some enterprises lack comprehensive understanding in the aspect of building resistance, so their consideration is not comprehensive. This results in that many construction projects cannot meet the standard and faces potential serious security threat.

B. Building structure lacks scientific nature and rationality

The scientific nature and rationality of building structures design directly affects the quality of building structure. In building design, there are many unreasonable situations. These situations produce adverse effect for building structure security and quality. Specifically, they mainly include: first, part of the construction workers are not in strict accordance with the relevant design criteria in building structure design, so the final design of the structure lacks rationality and science, and the result is far from the ideal result. There are some designers who lack strong professional knowledge and rich experience, which results in many problems appear in design process and cause many security hidden dangers. Second, some designers have little safety consciousness. They put no emphasis on safety and quality in design, but emphasis on design appearance, function, etc. The ignorance of security eventually will seriously affect the quality of construction projects. Third, in order to pursue their own interests, some building design personnel know that building structural design is unreasonable and cannot ensure safety and quality, but they did not pose any objection and eventually bring greater security hidden dangers. Building design personnel, therefore, should 
ensure the safety of people's lives and property as design principles, earnestly fulfill their work responsibilities, and maximally ensure the rational and scientific nature of building structure design.

\section{Reduce construction materials and lose the performance}

For the safety of structures, the choice of material is very critical. There are all kinds of quality problems in many buildings, which in large part are caused because the control of building materials does not reach the designated position. Some construction enterprises, in order to obtain greater economic benefits, buy some cheap poor quality materials which greatly reduce material performance and have serious impact on the quality of building structure. This also can cause many unnecessary accidents. For example, some construction enterprises buy some cold rolled deformed bars in order to save costs as much as possible. This type steel price is cheap, but the seismic ability is poorer with low wear resistance. Although they obtain economic benefits, it poses a threat to people's personal safety.

\section{BUILDING STRUCTURE DESIGN SECURITY OVERVIEW}

Building design contains a relatively wide range of professional knowledge. It is a comprehensive discipline. The calculation of construction safety not only involves the knowledge of two disciplines, namely architecture and physics, but also some factors of building shape structure and position so as to ensure safety construction. Before the design of building structures, the designers should comprehensively survey construction environment and soil conditions, and reasonably and scientifically design drawings knowing comprehensive overall situation to avoid the quality and safety problems caused by unreasonable design. In addition, the materials used in the process of construction also should be considered. Strictly control the use of materials, and at the same time also have a comprehensive consideration of geographical conditions, weather and the temperature factors in construction area to the scope of building design.

\section{CONSTRUCTION STRUCTURE DESIGN CHARACTERISTICS AND PRINCIPLES}

In construction engineering, building structure forms are varied, especially in high-rise building. Its structures and forms are more diversified and complicated. Building design, as a kind of engineering technology, includes the following several characteristics: one is application. A successful design for building structure needs to ensure that economic benefit is remarkable and technology is advanced and reasonable, economical and practical. Two is scientific. With continuous development of science and technology, building structure design needs advanced computer technology as the basis. Mathematical and mechanical knowledge are used as theoretic foundation to complete. A building structure designer should have a strong adaptive ability and understanding ability and is good at mathematics and mechanics to analyze working mechanism of structures. Three is practical. Building structure design is an engineering practice. A designer must have rich experience and must exercise for a long time to become a design engineer. Four is complexity. There are many uncertain factors in the design of building structures, which make building structure design present the characteristics of complexity. Five is innovative. In design market with increasingly fierce competition, building designers must provide novel design with economic and reasonable structure to achieve project developers. Designers should have advanced design idea and innovation ability to have a foothold in the fierce market competition.

In building structure design, we should follow certain principles, which mainly include building structural integrity principle, moderate elasticity principle and multiple protection principle. First is building structural integrity principle. The integrity of construction structures affects the overall quality and it ensures construction from damage. Therefore, in the design, the designer should follow the principle of integrity, maximally guarantee the clear pass of component stress relationship, dredge every joint in construction of building, and further reduce the force impact and increase the building bearing capacity. Second is moderate elasticity principle. If the stiffness of structures is too large, it is easy to cause deformation. In the event of an earthquake, the building structure would be damaged. If the structure is not hard enough, it will affect the stability. Therefore, 
building structures should maintain a moderate elasticity. Third is multiple protection principle. Single security building cannot protect the safety of building system. Only with multiple structure protection, the safety of the building can be guaranteed. So it can effectively resist the impact of external force and avoid unnecessary accidents. In addition, computer software can be used to verify building structure in detail in order to take multiple protection action.

\section{EFFECTIVE STRATEGIES TO IMPROVE THE SAFETY IN CONSTRUCTION DESIGN}

\section{A. Strictly abide by national building structure design rules}

With the rapid development of economy, construction industry is increasingly developed. In order to better adapt to the development of construction industry, our country promulgated and implemented some policies and regulations to regulate and constraint various behaviors in construction industry to ensure the quality and security of building. Therefore, building structure system designers should strictly follow the relevant specification, design in accordance with relevant provisions, and continuously reform and innovation to adapt to the development of The Times. Those behaviors not conforming to the provisions should be given a severe blow to avoid their effect on the quality of the building and causing unnecessary safe hidden troubles. Encourage designers to debunk the irregularities or illegal acts of others to fundamentally prevent potential safety hazard.

\section{B. Strengthen the seismic consciousness of building structure designer}

Building structure design is a comprehensive and systematic work, need to staff have rigorous earnest work attitude, flexible and innovative thinking mode. Structure designers should timely transform traditional ideas, strengthen the understanding of building seismic performance, and understand the importance of seismic performance to improve construction engineering safety. To be responsible to people's life and property safety, elaborately design each component and achieve excellence to improve the seismic effect of building structure design and guarantee the safety of building structure design.

C. Improve the specialized skill of building designer

In the environment of rapid construction development, building design technology level also increases year by year. It has put forward higher requirements for professional skills and comprehensive quality of building designers. In today's computer information age, computer technology is widely applied in various fields of industry, and the design of building structure also depends on professional software to better finish. Therefore, building structure designers should not only have solid professional knowledge and strong comprehensive quality, also have strong computer skills and fully grasp the operation of computer software. Regularly strengthen the training of building structure designers. Training contents include computer related skills, professional knowledge, comprehensive quality and sense of working responsibility, etc. Train a group of design talents with strong professional skills and higher comprehensive quality to make the design of building structure security guaranteed.

D. The innovation of software design

With the rapid development of economy, society is in constant progress. Any industry needs innovation and reform, otherwise it will face elimination crisis. As an industry with relatively rapid development in recent years, building design content and difficulty are becoming bigger and bigger. Traditional building design is difficult to meet the development of modern society and is also hard to meet people's needs. Therefore, it is required to strengthen innovation in building design. On the one hand, it requires designers to have deep knowledge and innovation consciousness to ensure that it can effectively expand the knowledge, and on the other hand they should fully consider the security of building design. Effectively combined with advanced computer technology, develop sophisticated and advanced design software, keep pace with The Times and thus better complete building design work and improve the safety of building design.

E. Strengthen safety supervision

In order to improve the security of structure design, intensify its supervision. This also cannot be ignored. Concretely this can be conducted through two aspects. First is to strictly review the 
construction equipment and materials, and forbid construction institutions use the materials and equipment that are not in conformity with the provisions, and strictly specify materials and equipment use. If behaviors of cutting corners or violation of the provisions are found, give severe punishment to ensure the safety. Second, strictly examine and supervise the whole process of building structure design, and implement the supervision and management on a regular basis. Review and check if the design is in compliance with related rules and regulations and check if there are any problems in design drawing. If any problem is found, timely put forward and correct.

\section{V.CONCLUSION}

Building design security relates with people's life and property safety, so it earns more and more attention of people. Building structure design is about the safety of structures; therefore, we should strengthen the attention on the safety of building structure design. Designers should have solid professional knowledge skills, and have high professional quality and sense of work responsibility. In building structure design, we should strictly abide by relevant laws and regulations and design scientific and rational schemes to practically improve the safety of building structure design and minimize unnecessary safety accidents.

\section{REFERENCES}

[1] Li Bo, Shi Guodong. On how to improve building safety in building structure design [J]. Journal of Information Science and Technology, 2012, 39 (24) : 40 and 41.

[2] Ma Fenglian, Shi Zhipeng. The suggestions to improve construction safety in the design of building structure [J]. Science and Technology Innovation and Application, 2012 (15) : 228-228.

[3] Chen Yuan. How to improve construction safety analysis in the design of building structure [J]. Journal of Enterprise Science and Technology and Development, 2015 (17) : 69-70.

[4] Zhou Qiyan. How to improve construction safety analysis in the design of building structure [J]. Journal of Enterprise Science and Technology and Development, 2015 (9) : 83-84.

[5] Huang Chiliang. Construction safety consideration in the design of building structure [J]. Journal of Building Knowledge: Academic Journal, 2013 (B08) : 69-69.

[6] Gao Song. Suggestions to improve construction safety in the design of building structure [J]. Science and Technology and Enterprise, 2014 (3) : 61-61. 